\title{
Estimated glomerular filtration rate and daily amount of urinary protein predict the clinical remission rate of tonsillectomy plus steroid pulse therapy for IgA nephropathy
}

\author{
Keisuke Suzuki • Naoto Miura · Hirokazu Imai
}

Received: 28 March 2013/Accepted: 31 August 2013/Published online: 20 September 2013

(c) The Author(s) 2013. This article is published with open access at Springerlink.com

\begin{abstract}
Background This retrospective study was designed to estimate the clinical remission (CR) rate of tonsillectomy plus steroid pulse (TSP) therapy in patients with IgA nephropathy.

Methods Based on 292 of 302 patients with $\operatorname{IgA}$ nephropathy treated at 11 Japanese hospitals, we constructed heat maps of the CR rate at 1 year after TSP with the estimated glomerular filtration rate (eGFR), grade of hematuria, pathological grade, number of years from diagnosis until TSP, and age at diagnosis on the vertical axis and the daily amount of urinary protein (urinary protein) on the horizontal axis. We compared subgroups usinge Student's $t$ test, the chi-square test with Yates correction, or Fisher's exact probability test.

Results The first heat map of eGFR and urinary protein showed that the CR rate was $71 \%$ (CR vs. non-CR, 96 vs. 40) in patients with eGFR greater than $30 \mathrm{ml} / \mathrm{min} / 1.73 \mathrm{~m}^{2}$ and $0.3-1.09 \mathrm{~g} /$ day of urinary protein. However, the CR rate in patients with more than $1.50 \mathrm{~g}$ /day of urinary protein was approximately $30 \%$. The second heat map of grade of hematuria and urinary protein revealed that the CR rate is $72 \%$ (CR vs. non-CR, 93 vs. 37) in patients with more than $1+$ hematuria and $0.3-1.09 \mathrm{~g} /$ day of urinary protein; however, it was $28.6 \%$ in patients with no
\end{abstract}

\footnotetext{
K. Suzuki · N. Miura $\cdot$ H. Imai $(\bowtie)$

Division of Nephrology and Rheumatology, Department

of Internal Medicine, Aichi Medical University School

of Medicine, Nagakute, Aichi 480-1195, Japan

e-mail: imaihiro@aichi-med-u.ac.jp

K. Suzuki

e-mail: keisukes@aichi-med-u.ac.jp

N. Miura

e-mail: naoto@aichi-med-u.ac.jp
}

hematuria. The third heat map of pathological grade and urinary protein demonstrated that the highest $\mathrm{CR}$ rate was $83 \%$ (CR vs. non-CR, 52 vs. 11) in patients with pathological grade I or II disease and less than $1.09 \mathrm{~g} /$ day of urinary protein, as opposed to $22 \%$ (CR vs. non-CR, 9 vs. 32 ) in patients with pathological grade III or IV disease and more than $2.0 \mathrm{~g} /$ day of urinary protein. The fourth heat map of the number of years from diagnosis until TSP and urinary protein revealed that the former did not influence the CR rate in patients with less than $1.09 \mathrm{~g} /$ day of urinary protein. However, in patients with more than $1.10 \mathrm{~g} /$ day of urinary protein, the $\mathrm{CR}$ rate of the subgroup with less than 6 years was $43 \%$ (CR vs. non-CR; 23 vs. 54) compared to $23 \%$ (CR vs. non-CR, 11 vs. $48 ; P=0.01$ ) in the subgroup with more than 6 years. The fifth heat map of age at diagnosis and urinary protein showed that the CR rate is approximately $72 \%$ (CR vs. non-CR, 73 vs. 28) in patients older than 19 years at diagnosis with $0.3-1.09 \mathrm{~g} /$ day of urinary protein.

Conclusions The daily amount of urinary protein is an important predictor of the CR rate after TSP in $\operatorname{IgA}$ nephropathy patients. Heat maps are useful tools for predicting the CR rate associated with TSP.

Keywords Clinical remission - Heat map · IgA nephropathy · Tonsillectomy plus steroid pulse therapy

\section{Introduction}

In 2001, Hotta et al. [1] proposed tonsillectomy plus steroid pulse (TSP) as a new approach that can induce clinical remission (CR) in IgA nephropathy patients. The profile of 329 patients in their retrospective study was as follows: age 
(mean $\pm \mathrm{SD}), \quad 36.1 \pm 12.8$ years; daily proteinuria, $1.40 \pm 1.09 \mathrm{~g}$; serum creatinine, $1.14 \pm 0.48 \mathrm{mg} / \mathrm{dl}$. In a Cox regression analysis with 13 variables, serum creatinine $<1.3 \mathrm{mg} / \mathrm{dl}$, daily proteinuria between 0.5 and $1.5 \mathrm{~g}$, histological score (index of glomerular lesion, calculated by the degree of mesangial proliferation and sclerosis) $<2.00$, steroid pulse therapy, and tonsillectomy were identified as prognostic factors for CR. Recently, a subsequent analysis revealed that each year 600 patients in Japan received TSP in 2006 [2]. In 2010, more than 1,000 patients per year received TSP in Japan, with half achieving CR, defined as no urinary abnormalities, 1 year after treatment. In a retrospective multicenter study, Miura et al. found that $54.1 \%$ of patients reached CR at 1 year after TSP. There were significant differences between patients who reached $\mathrm{CR}$ and those who did not reach $\mathrm{CR}$ in terms of the number of years from diagnosis until TSP $(P=0.02)$, daily proteinuria $(P<0.0001)$, serum creatinine $(P=0.006)$, and pathological grade $(P=0.0006)$. Multivariate logistic regression analysis demonstrated that factors associated with resistance to TSP include young age, massive amounts of urinary protein, absence of hematuria, and severe pathological grade. Our present study was designed to clarify the indications and limitations of TSP for IgA nephropathy patients and to clarify whether a heat map, by using several factors on vertical axis and daily amount of urinary protein on horizontal axis, can predict CR.

\section{Methods}

The present retrospective multicenter study was approved by the Ethics Committee of Aichi Medical University and was designed as a sub-analysis of previously reported data.

\section{Patients}

From our previous study involving 303 patients [2], 292 with sufficient laboratory data such as the daily amount of urinary protein and serum creatinine values were analyzed here. The present study included 128 males and 164 females, whose mean age was $34.17 \pm 13.75$ years (range, 12-73). The mean duration from diagnosis to TSP was $6.1 \pm 6.1$ years. The daily amount of urinary protein was $1.10 \pm 1.29 \mathrm{~g}$, and the serum creatinine level was $0.93 \pm 0.38 \mathrm{mg} / \mathrm{dl}$. There were 14, 47, 74, and 157 patients with hematuria grade $0,1+, 2+$, and $3+$, respectively. The distribution of pathological grade was: I, 14 patients; II, 57 patients; III, 120 patients; IV, 101 patients. The prevalence of antihypertensive medication use was $41.6 \%$. The CR rate at 1 year after TSP was $55.5 \%$. Previous studies using multivariate logistic regression have identified several factors that predict resistance to TSP such as age at diagnosis, daily amount of urinary protein, hematuria, and pathological grade. The use of angiotensin-converting enzyme inhibitors or angiotensin II receptor blockers and gender had no impact on $\mathrm{CR}$ in previous studies.

\section{The definition of CR}

CR was determined based on urinary analysis, as described in a previous report [2]. Remission of proteinuria was defined as negative $(-)$ or trace $( \pm)$ proteinuria on the urine dipstick test, while remission of hematuria was specified as the absence of blood on the dipstick test and urinalysis. CR was defined as the complete resolution of both proteinuria and hematuria.

\section{Estimation of the glomerular filtration rate (GFR)}

The estimated GFR (eGFR) was calculated using the Japanese equation [3]:

$$
\begin{aligned}
& \operatorname{eGFR}\left(\mathrm{ml} / \mathrm{min} / 1.73 \mathrm{~m}^{2}\right)=194 \times \mathrm{Cr}^{-1.094} \times \mathrm{age}^{-0.287} \\
& \quad \times(0.739 \text { if female })
\end{aligned}
$$

Pathological grade

Pathological grade of the kidney biopsy was assessed by pathologists or nephrologists at each participating hospital during using the previous criteria from the Joint Committee of the Research Group on Progressive Renal Diseases and the Japanese Society of Nephrology [4].

Biopsy samples were graded based on the following criteria:

Grade I: Glomerular findings: Slight mesangial cell proliferation and increased matrix. Glomerulosclerosis, crescent formation, or adhesion to Bowman's capsule is not observed. Interstitial and vascular findings: Prominent changes are not seen in the interstitium, renal tubuli, or blood vessels.

Grade II: Glomerular findings: Slight mesangial cell proliferation and increased matrix. Glomerulosclerosis, crescent formation, or adhesion to Bowman's capsule seen in $<10 \%$ of all biopsied glomeruli. Interstitial and vascular findings: Prominent changes are not seen in the interstitium, renal tubuli, or blood vessels.

Grade III: Glomerular findings: Moderate, diffuse mesangial cell proliferation and increased matrix. Glomerulosclerosis crescent formation or adhesion to Bowman's capsule seen in 10-30 \% of all biopsied glomeruli. Interstitial and vascular findings: Cellular infiltration is slight in the interstitium except around some sclerosed glomeruli. Tubular atrophy is slight, and mild vascular sclerosis is observed. 
Grade IV: Glomerular findings: Severe, diffuse cell proliferation and increased matrix. Glomerulosclerosis, crescent formation, or adhesion to Bowman's capsule seen in $>30 \%$ of all biopsied glomeruli. When sites of sclerosis are totaled and converted to global sclerosis, the sclerosis rate is $>50 \%$ of all glomeruli. Some glomeruli also show compensatory hypertrophy. The sclerosis rate is the most important of these indices. Interstitial and vascular findings: Interstitial cellular infiltration and tubular atrophy, as well as fibrosis are seen. Hyperplasia or degeneration may be seen in some intrarenal arteriolar walls.

\section{Construction of the $\mathrm{CR}$ rate heat maps}

Clinical remission was shown as " $\mathrm{C}$ " and non-clinical remission as "N." The CR rate was calculated in each cell. Cells were color coded by the CR rate with $>66 \%$ represented by dark blue, $50-65 \%$ by light blue, $50 \%$ by yellow, 33-49 \% by orange, $<33 \%$ by dark red, and patient number zero by white.

The first heat map (Fig. 1) shows the CR rate according to eGFR and urinary protein levels. eGFR, depicted on the vertical axis, was divided into eight subgroups with eGFR $>90,80-89,70-79,60-69,50-59,40-49,30-39$, and $15-29 \mathrm{ml} / \mathrm{min} / 1.73 \mathrm{~m}^{2}$, respectively. Urinary protein was divided into nine subgroups: $<0.29,0.30-0.49,0.50-0.69$, $0.70-0.89,0.90-1.09,1.10-1.49,1.50-1.99,2.00-2.99$, and $>3.00 \mathrm{~g} /$ day. The second heat map (Fig. 2) has the grade of hematuria on the vertical axis and urinary protein on the horizontal axis. The third heat map (Fig. 3) has the pathological grade on the vertical axis and urinary protein on the horizontal axis. A fourth heat map, with the number of years from diagnosis until TSP on the vertical axis and urinary protein on the horizontal axis, was also constructed (Fig. 4). The number of years from diagnosis until TSP was divided into five subgroups: <1.0, 1.0-2.99, 3.0-5.99, 6.0-8.99, 9.0-14.99, and $>15.0$ years, respectively. A fifth heat map was constructed using age at diagnosis on the vertical axis and urinary protein on the horizontal axis (Fig. 5). Age at diagnosis was divided into six subgroups: $<19$, 20-29, 30-39, 40-49, 50-59, and >60 years.

\section{Statistical analysis}

Quantitative values were expressed as mean $\pm \mathrm{SD}$, unless otherwise noted. Data comparisons were carried out using Student's $t$ test or the chi-square test with the Yates correction for continuity or Fisher's exact probability test. $P$ values $<0.05$ were considered statistically significant.

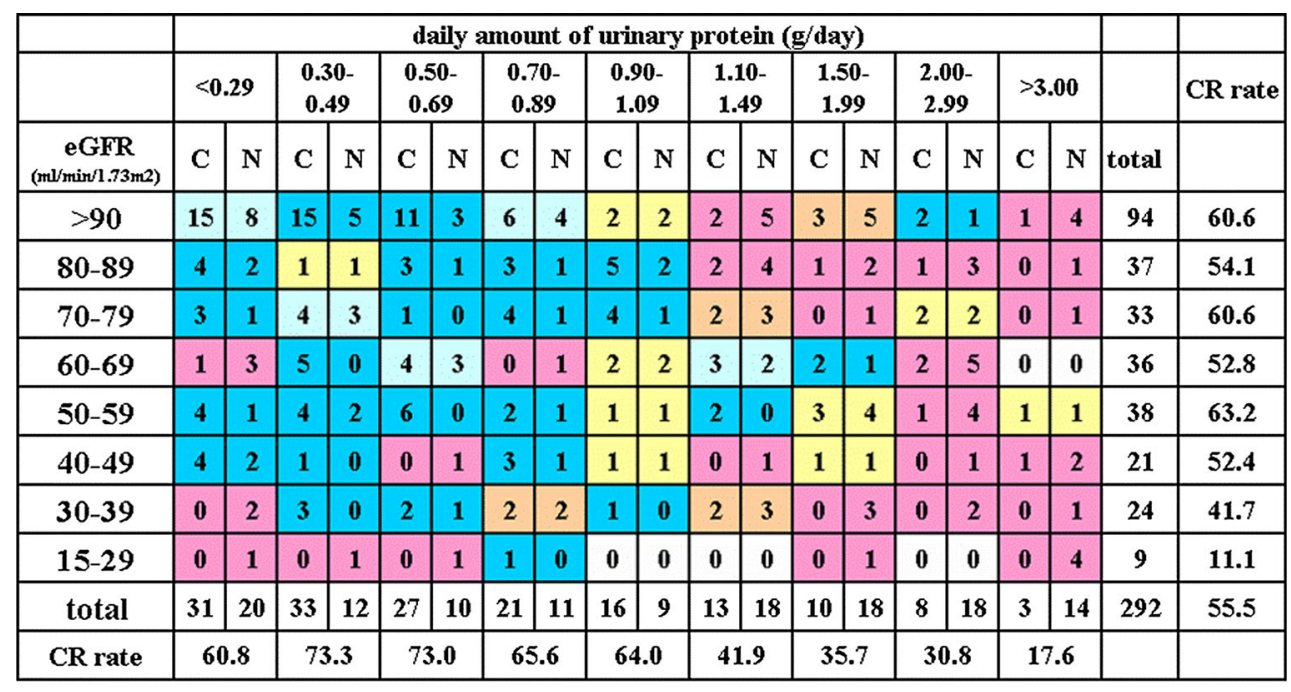

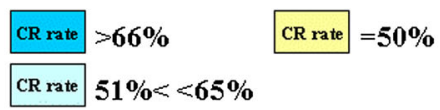

Fig. 1 A heat map of the CR rate based on the eGFR value and daily amount of urinary protein. A gradation from dark blue in the upper left corner to dark red in the lower right corner is observed. A relatively high CR rate of $71 \%$ (CR vs. non-CR, 96 vs. 40) was observed in patients with eGFR greater than $30 \mathrm{ml} / \mathrm{min} / 1.73 \mathrm{~m}^{2}$ and $0.3-1.09 \mathrm{~g} /$ day of urinary protein. On the other hand, the CR rate in patients with more than $1.50 \mathrm{~g} /$ day of urinary protein was $29.6 \%$ (CR

\begin{tabular}{l|l} 
CR rate $34 \%<<49 \%$ \\
\hline CR rate $<33 \%$
\end{tabular}

white no patients

C: patient number of clinical remission $\mathrm{N}$ : patient number of not-clinical remission

vs. non-CR, 21 vs. 50). The CR rate in patients with hematuria alone $(<0.29 \mathrm{~g} /$ day of urinary protein) was relatively low at $60.8 \%$ (CR vs. non-CR, 31 vs. 20), compared to $73 \%$ (CR vs. non-CR, 60 vs. 22) in patients with $0.3-0.69 \mathrm{~g} /$ day of urinary protein $(P=0.19)$. Patients with $<0.29 \mathrm{~g} /$ day of urinary protein and eGFR of $60-69 \mathrm{ml} / \mathrm{min} /$ $1.73 \mathrm{~m}^{2}$ have a low $\mathrm{CR}$ rate; however, there is no significant difference among these subgroups 
Fig. 2 A heat map of the CR rate based on the grade of hematuria and daily amount of urinary protein. A graduation from dark blue in the upper left corner to dark red in the lower right corner is observed.

Patients with no hematuria had a worse $\mathrm{CR}$ rate, $28.6 \%$ (CR vs. non-CR, 4 vs. 10), compared to subgroups with hematuria (56\%; CR vs. non-CR, 158 vs. 124; $P=0.04)$. The $\mathrm{CR}$ rate was $72 \%$ (CR vs. non-CR, 108 vs. 49) in patients with more than $1+$ hematuria and $0.3-0.89 \mathrm{~g} /$ day of urinary protein. The CR rate was $25.6 \%$ (CR vs. non-CR, 11 vs. 32 ) in patients with more than $1+$ hematuria and more than $2.0 \mathrm{~g} /$ day of urinary protein

\begin{tabular}{|c|c|c|c|c|c|c|c|c|c|c|c|c|c|c|c|c|c|c|c|c|}
\hline \multirow[b]{3}{*}{$\begin{array}{c}\text { hematuria } \\
\text { (grade) }\end{array}$} & \multicolumn{18}{|c|}{ daily amount of urinary protein (g/day) } & & \\
\hline & \multicolumn{2}{|c|}{$<0.29$} & \multicolumn{2}{|c|}{$\begin{array}{c}0.30- \\
0.49\end{array}$} & \multicolumn{2}{|c|}{$\begin{array}{l}0.50- \\
0.69\end{array}$} & \multicolumn{2}{|c|}{$\begin{array}{l}0.70- \\
0.89\end{array}$} & \multicolumn{2}{|c|}{$\begin{array}{l}0.90- \\
1.09\end{array}$} & \multicolumn{2}{|c|}{$\begin{array}{l}1.10- \\
1.49\end{array}$} & \multicolumn{2}{|c|}{$\begin{array}{l}1.50- \\
1.99\end{array}$} & \multicolumn{2}{|c|}{$\begin{array}{l}2.00- \\
2.99\end{array}$} & \multicolumn{2}{|c|}{$>3.00$} & & \multirow[t]{2}{*}{ CR rate } \\
\hline & $\mathbf{C}$ & $\mathbf{N}$ & $\mathrm{C}$ & $\mathrm{N}$ & C & $\mathrm{N}$ & $\mathrm{C}$ & $\mathbf{N}$ & $\mathrm{C}$ & $\mathrm{N}$ & $\mathrm{C}$ & $\mathbf{N}$ & $\mathbf{C}$ & $\mathbf{N}$ & $\mathrm{C}$ & $\mathbf{N}$ & C & $\mathbf{N}$ & total & \\
\hline 0 & o & 1 & 0 & 1 & 2 & 2 & 1 & 0 & 1 & 2 & 0 & 1 & 0 & 3 & $\mathbf{0}$ & 0 & $\mathbf{0}$ & $\mathbf{0}$ & 14 & 28.6 \\
\hline 1 & 9 & 6 & 5 & $\mathbf{0}$ & 2 & $\mathbf{0}$ & 4 & 1 & 2 & 2 & 1 & 4 & 3 & 3 & 1 & 3 & 1 & 0 & 47 & 59.6 \\
\hline 2 & 8 & 3 & 7 & 6 & 9 & 4 & 6 & 3 & 4 & 2 & 5 & 5 & 2 & 2 & 1 & 4 & 0 & 3 & 74 & 56.8 \\
\hline 3 & 14 & 10 & 21 & 5 & 14 & 4 & 10 & 7 & 9 & 3 & 7 & 8 & 5 & 10 & 6 & 11 & 2 & 11 & 157 & 56.1 \\
\hline total & 31 & 20 & 33 & 12 & 27 & 10 & 21 & 11 & 16 & 9 & 13 & 18 & 10 & 18 & 8 & 18 & 3 & 14 & 292 & 55.5 \\
\hline CR rate & 60 & .8 & 73 & & 73 & .0 & 65 & .6 & 0 & & & & 35 & .7 & & .8 & & .6 & & \\
\hline
\end{tabular}

\begin{tabular}{|c|c|c|c|c|c|}
\hline CR rate & $>66 \%$ & CR rate & $=50 \%$ & CR rate & $34 \%<<49 \%$ \\
\hline CR rate & $51 \%<<65 \%$ & & & CR rate & $<33 \%$ \\
\hline
\end{tabular}

white = no patients

$C$ : patient number of clinical remission $\mathrm{N}$ : patient number of not-clinical remission
Fig. 3 A heat map of the CR rate based on pathological grade and daily amount of urinary protein. A gradation from dark blue in the upper left corner to dark red in the lower right corner is observed. The $\mathrm{CR}$ rate of patients with pathological grade I or II disease and $<1.09 \mathrm{~g}$ of daily urinary protein was $82.5 \%$ (CR vs. non-CR, 52 vs. 11). In contrast, the $C R$ rate of patients with pathological grade III or IV disease and more than $2.0 \mathrm{~g}$ of daily urinary protein was $28.1 \%$ (CR vs. non-CR, 9 vs. $32 ; P<0.00001)$

\begin{tabular}{|c|c|c|c|c|c|c|c|c|c|c|c|c|c|c|c|c|c|c|c|c|}
\hline \multirow{3}{*}{$\begin{array}{c}\text { pathological } \\
\text { grade }\end{array}$} & \multicolumn{18}{|c|}{ daily amount of urinary protein (g/day) } & & \multirow{3}{*}{ CR rate } \\
\hline & \multicolumn{2}{|c|}{$<0.29$} & \multicolumn{2}{|c|}{$0.3-0.49$} & \multicolumn{2}{|c|}{$0.5-0.69$} & \multicolumn{2}{|c|}{$0.70-0.89$} & \multicolumn{2}{|c|}{$0.90-1.09$} & \multicolumn{2}{|c|}{$1.10-1.49$} & \multicolumn{2}{|c|}{$1.50-1.99$} & \multicolumn{2}{|c|}{$2.00-2.99$} & \multicolumn{2}{|c|}{$>3.00$} & & \\
\hline & C & $\mathrm{N}$ & $\mathbf{C}$ & $\mathbf{N}$ & C & $\mathbf{N}$ & C & $\mathbf{N}$ & C & $\mathbf{N}$ & C & $\mathbf{N}$ & C & $\mathbf{N}$ & C & $\mathbf{N}$ & $\mathrm{C}$ & $\mathbf{N}$ & total & \\
\hline I & 3 & 2 & 5 & 0 & 2 & 1 & $\mathbf{0}$ & 0 & $\mathbf{0}$ & $\mathbf{0}$ & $\mathbf{0}$ & 1 & 0 & 0 & $\mathbf{0}$ & 0 & $\mathbf{0}$ & 0 & 14 & 71.4 \\
\hline II & 14 & 3 & 11 & 2 & 6 & 1 & 3 & 2 & 8 & 0 & 1 & 1 & 0 & 3 & 1 & 0 & 1 & 0 & 57 & 78.9 \\
\hline III & 7 & 7 & 12 & 6 & 13 & 5 & 7 & 4 & 6 & 4 & 7 & 10 & 5 & 8 & 3 & 8 & 1 & 7 & 120 & 50.8 \\
\hline IV & 7 & 8 & 5 & 4 & 6 & 3 & 11 & 5 & 2 & 5 & 5 & 6 & 5 & 7 & 4 & 10 & 1 & 7 & 101 & 45.5 \\
\hline total & 31 & 20 & 33 & 12 & 27 & 10 & 21 & 11 & 16 & 9 & 13 & 18 & 10 & 18 & 8 & 18 & 3 & 14 & 292 & 55.5 \\
\hline CR rate & 60 & .8 & & & 73 & & & .6 & 6 & .0 & & .9 & & .7 & & 1.8 & & .6 & & \\
\hline
\end{tabular}

\begin{tabular}{|c|c|c|c|c|c|}
\hline CR rate & $>66 \%$ & CR rate & $=\mathbf{5 0} \%$ & CR rate & $34 \%$ \\
\hline CR rate & $51 \%<<65 \%$ & & & CR rate & $<33 \%$ \\
\hline
\end{tabular}

white = no patients

C: patient number of clinical remission $N$ : patient number of not-clinical remission

\section{Results}

The CR rate according to eGFR and urinary protein levels

Figure 1 shows a heat map of the CR rate at 1 year after TSP for IgA nephropathy patients, which demonstrates a gradient from high to low CR rates. There is a significant difference between subgroups with less than $1.09 \mathrm{~g} /$ day of proteinuria (CR vs. non-CR, 128 vs. 62) and more than
$1.10 \mathrm{~g} /$ day (CR vs. non-CR, 34 vs. $68 ; P<0.00001$ ). A high $\mathrm{CR}$ rate of $71 \%$ (CR vs. non-CR, 96 vs. 40) was observed in patients with eGFR levels greater than $30 \mathrm{ml} /$ $\mathrm{min} / 1.73 \mathrm{~m}^{2}$ and $0.3-1.09 \mathrm{~g} /$ day of urinary protein. On the other hand, the CR rate in the subgroup with more than $1.50 \mathrm{~g} /$ day of urinary protein was $29.6 \%$. In contrast, the $\mathrm{CR}$ rate was as low as $60.8 \%$ in patients with hematuria alone $(<0.29 \mathrm{~g} /$ day of urinary protein; $\mathrm{CR}$ vs. non-CR, 31 vs. 20) compared to $73 \%$ in patients with $0.3-0.69 \mathrm{~g} /$ day of urinary protein (CR vs. non-CR, 60 vs. $22 ; P=0.19$ ). 
Patients with $<0.29 \mathrm{~g} /$ day of urinary protein and $60-69 \mathrm{ml} /$ $\min / 1.73 \mathrm{~m}^{2}$ of eGFR had a low CR rate, but there was no significant difference.

The CR rate according to the grade of hematuria and urinary protein

Figure 2 shows that the CR rate was $72 \%$ (CR vs. nonCR, 108 vs. 49 ) in patients with more than $1+$ hematuria and $0.3-0.89 \mathrm{~g} /$ day of urinary protein; however, the CR rate was $28.6 \%$ in patients without hematuria (14 out of 292 patients). The $\mathrm{CR}$ rate of the $1+, 2+$, and $3+$ hematuria subgroups was 59.6, 56.8, and $56.1 \%$, respectively.

The CR rate according to pathological grade and urinary protein

Figure 3 demonstrates that the $\mathrm{CR}$ rate in patients with pathological grade I or II disease and $<1.09 \mathrm{~g} /$ day of
Fig. 4 A heat map of the CR rate based on the number of years from diagnosis until TSP and daily amount of urinary protein. A gradation from dark blue starting to the left of $1.09 \mathrm{~g}$ of daily urinary protein to dark red on the right is observed. In patients with daily urinary protein between 0.3 and $1.09 \mathrm{~g}$, the number of years from diagnosis until TSP did not influence the $\mathrm{CR}$ rate, which was in the $70 \%$ range.

However, in patients with more than $1.10 \mathrm{~g} /$ day of urinary protein, the $\mathrm{CR}$ rate of the subgroup with less than 6 years was $43 \%$ (CR vs. non-CR, 23 vs. 54) compared to $23 \%$ in the subgroup with more than 6 years (CR vs. non-CR, 11 vs. $48 ; P=0.01)$

Fig. 5 A heat map of the CR rate based on the age at diagnosis and daily amount of urinary protein. A graduation from dark blue starting from the lower left of $0.3-0.89 \mathrm{~g}$ of urinary protein to dark red on the right is observed. The CR rate was $73 \%$ (CR vs. non-CR, 88 vs. 35 ) in patients with $0.3-1.09 \mathrm{~g} /$ day of urinary protein who were older than 20 years at diagnosis. However, relatively low CR rates of 52.8 and $42.2 \%$ were found in patients $<19$ years old and between 40 and 49 years old at diagnosis, respectively

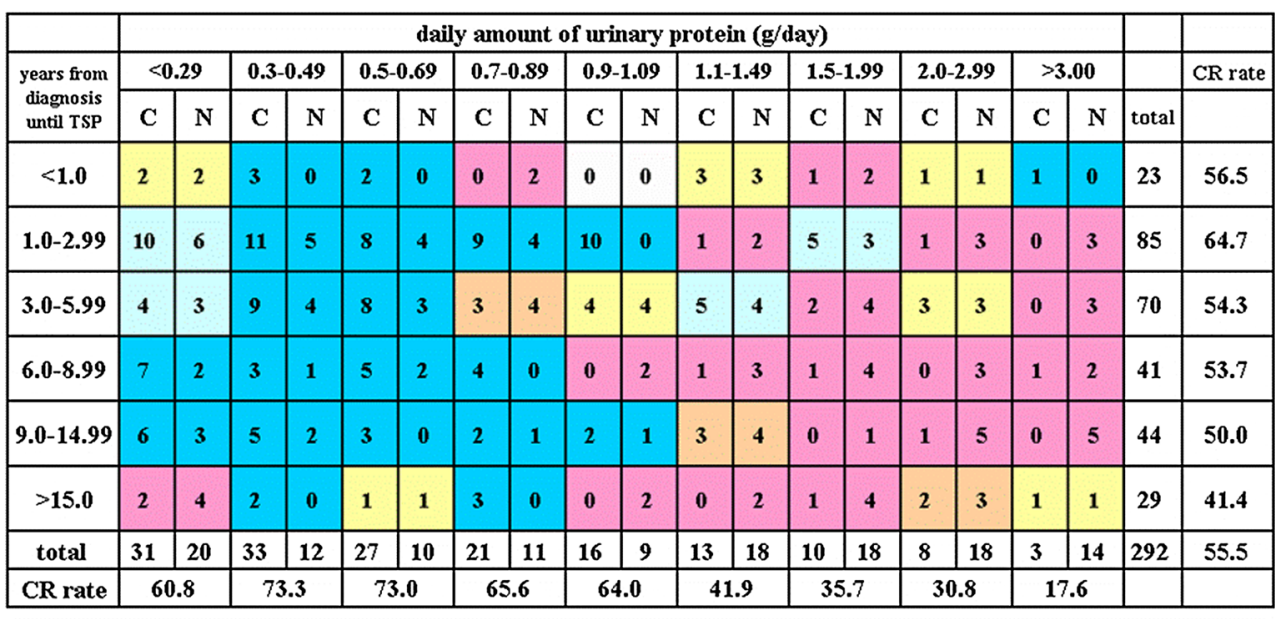

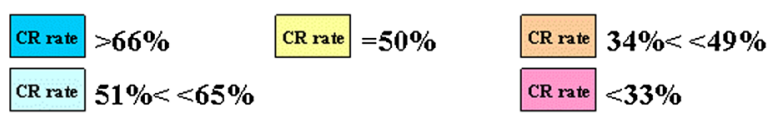

white = no patients

C: patient number of clinical remission $\mathrm{N}$ : patient number of not-clinical remission

\begin{tabular}{|c|c|c|c|c|c|c|c|c|c|c|c|c|c|c|c|c|c|c|c|c|}
\hline \multirow[b]{3}{*}{$\begin{array}{c}\text { age at } \\
\text { diagnosis }\end{array}$} & \multicolumn{18}{|c|}{ daily amount of urinary protein ( $\mathrm{g} /$ day) } & & \multirow{3}{*}{ CR rate } \\
\hline & \multicolumn{2}{|c|}{$<0.29$} & \multicolumn{2}{|c|}{$\begin{array}{l}0.30- \\
0.49\end{array}$} & \multicolumn{2}{|c|}{$\begin{array}{l}0.50- \\
0.69\end{array}$} & \multicolumn{2}{|c|}{$\begin{array}{l}0.70- \\
0.89\end{array}$} & \multicolumn{2}{|c|}{$\begin{array}{l}0.90- \\
1.09\end{array}$} & \multicolumn{2}{|c|}{$\begin{array}{l}1.10- \\
1.49\end{array}$} & \multicolumn{2}{|c|}{$\begin{array}{l}1.50- \\
1.99 \\
\end{array}$} & \multicolumn{2}{|c|}{$\begin{array}{c}2.00- \\
2.99 \\
\end{array}$} & \multicolumn{2}{|c|}{$>3.00$} & & \\
\hline & C & $\mathrm{N}$ & $\mathrm{C}$ & $\mathbf{N}$ & C & $\mathrm{N}$ & $\mathrm{C}$ & $\mathrm{N}$ & C & $\mathrm{N}$ & $\mathrm{C}$ & $\mathrm{N}$ & C & $\mathrm{N}$ & $\mathrm{C}$ & $\mathrm{N}$ & C & $\mathrm{N}$ & total & \\
\hline$<19$ & 8 & 4 & 5 & 3 & 1 & 2 & 2 & 2 & 1 & 2 & 1 & 2 & 1 & 1 & 0 & 0 & 0 & 1 & 36 & 52.8 \\
\hline $20-29$ & 11 & 6 & 12 & 4 & 10 & 4 & 3 & 4 & 6 & 3 & 2 & 10 & 3 & 8 & 5 & 4 & 1 & 3 & 99 & 53.5 \\
\hline $30-39$ & 7 & 2 & 3 & 2 & 5 & 1 & 10 & 2 & 4 & 1 & 3 & 1 & 2 & 2 & 2 & 9 & 2 & 3 & 61 & 62.3 \\
\hline $40-49$ & 2 & 2 & 4 & 3 & 3 & 2 & 2 & 1 & 3 & 3 & 3 & 4 & 1 & 3 & 1 & 3 & o & 5 & 45 & 42.2 \\
\hline $50-59$ & 2 & 5 & 6 & 0 & 6 & 1 & 2 & 2 & 2 & 0 & 4 & 0 & 2 & 1 & 0 & 2 & 0 & 2 & 37 & 64.9 \\
\hline $60<$ & 1 & 1 & 3 & 0 & 2 & o & 2 & 0 & $\mathbf{0}$ & $\mathbf{0}$ & 0 & 1 & 1 & 3 & 0 & 0 & 0 & 0 & 14 & 64.3 \\
\hline total & 31 & 20 & 33 & 12 & 27 & 10 & 21 & 11 & 16 & 9 & 13 & 18 & 10 & 18 & 8 & 18 & 3 & 14 & 292 & 55.5 \\
\hline CR rate & 60 & .8 & & & & & & 6 & & & & 9 & 35 & & & .8 & & & & \\
\hline
\end{tabular}

\begin{tabular}{|c|c|c|c|c|c|}
\hline CR rate & $>66 \%$ & CR rate & $=\mathbf{5 0} \%$ & CR rate & $34 \%<<49 \%$ \\
\hline CR rate & $51 \%<<65 \%$ & & & CR rate & $<33 \%$ \\
\hline
\end{tabular}

C: patient number of clinical remission $\mathrm{N}$ : patient number of not-clinical remission 
urinary protein was $82.5 \%$ (CR vs. non-CR, 52 vs. 11), whereas the subgroup with pathological grade III or IV disease and more than $2.0 \mathrm{~g} /$ day of urinary protein had a CR rate of $28.1 \%$ (CR vs. non-CR, 9 vs. 32; $P<0.00001$ ). The former subgroup had the highest $\mathrm{CR}$ rate, while the latter had the lowest CR rate.

The CR rate according to the number of years from diagnosis until TSP and urinary protein

Figure 4 shows that the number of years from diagnosis until TSP did not influence the CR rate in patients with between 0.3 and $1.09 \mathrm{~g} /$ day of urinary protein. The $\mathrm{CR}$ rate was approximately $70 \%$ in these subgroups. However, in patients with more than $1.10 \mathrm{~g} /$ day of urinary protein, the CR rate of the subgroup with less than 6 years was $43 \%$ (CR vs. non-CR, 23 vs. 54), compared to $23 \%$ for the subgroup with more than 6 years (CR vs. non-CR, 11 vs. $48 ; P=0.01$ ).

The CR rate according to the age at diagnosis and urinary protein level

Figure 5 shows that the CR rate was $73 \%$ (CR vs. non-CR; 88 vs. 35) in patients with between 0.3 and $1.09 \mathrm{~g} /$ day of urinary protein who were more than 20 years old at diagnosis. However, relatively low CR rates of 52.8 and $42.2 \%$ were found in patients $<19$ years old and between 40 and 49 years old, respectively.

There was no relationship between the number of years from diagnosis until TSP and pathological grade or eGFR, respectively (data not shown).

\section{Discussion}

This study revealed three major points. The first is that heat maps, based on eGFR and urinary protein, or pathological grade and urinary protein, can predict the CR rate at 1 year after TSP therapy in patients with $\operatorname{IgA}$ nephropathy. The second is that urinary protein is an important factor influencing the CR rate among the variables studied, which also included grade of hematuria, pathological grade, number of years from diagnosis until TSP, and age at diagnosis. The third is that patients with proteinuria alone (without hematuria) or hematuria alone $(<0.29 \mathrm{~g} /$ day of urinary protein) have relatively low CR rates of 28.5 and $60.8 \%$, respectively.

Heat maps are useful tools for physicians to predict the $\mathrm{CR}$ rate in individual patients and to explain the predicted $\mathrm{CR}$ rate to patients and their families. The highest $\mathrm{CR}$ rate was $82.5 \%$ in patients with pathological grade I or II disease and $<1.09 \mathrm{~g} /$ day of urinary protein, and approximately $70 \%$ in patients with eGFR $>30 \mathrm{ml} / \mathrm{min} / 1.73 \mathrm{~m}^{2}$ and $<1.09 \mathrm{~g} /$ day of urinary protein. These subgroups are good candidates for TSP. On the other hand, a poor CR rate of approximately $30 \%$ was observed in patients with more than $1.5 \mathrm{~g} /$ day of urinary protein regardless of eGFR. A randomized controlled trial comparing TSP, steroid pulse therapy, and antiplatelet drugs is needed to clarify the best treatment for IgA nephropathy patients with $<1.09 \mathrm{~g} /$ day of urinary protein, because observations on long-term outcomes of $\operatorname{IgA}$ nephropathy with minimal or no proteinuria have revealed that $37.5 \%$ of patients reach $\mathrm{CR}$ after a median of 48 months [5].

Recently, Ieiri et al. [6] emphasized that a shorter duration from diagnosis until TSP is associated with a high likelihood of CR in IgA nephropathy patients treated with TSP. In our previous study, the comparison between patients who reached $\mathrm{CR}$ and those who did not reach $\mathrm{CR}$ revealed significant differences in the number of years from diagnosis until TSP $(P=0.02)$, daily proteinuria $(P<0.0001)$, serum creatinine $(P=0.006)$, and pathological grade $(P=0.0006)$. However, multivariate logistic regression analysis did not identify the number of years from diagnosis until TSP as a predictive factor. The present study also revealed that the number of years from diagnosis until TSP does not necessarily influence the CR rate; when patients have between 0.3 and $1.09 \mathrm{~g} /$ day of urinary protein, the CR rate is approximately $70 \%$, independent of the number of years from diagnosis until TSP. On the other hand, the number of years form diagnosis until TSP is an important factor in patients with more than $1.1 \mathrm{~g} /$ day of urinary protein, because the CR rate was $23 \%$ in patients with more than 6 years from diagnosis until TSP compared to $43 \%$ in patients with $<6$ years from diagnosis until TSP $(P=0.01)$. The above results suggest that urinary protein is a more essential predictive factor than the number of years from diagnosis until TSP.

Regarding resistance to TSP, based on multivariate logistic regression analysis we previously reported that resistance to TSP therapy depends on age at diagnosis, urinary proteinuria, grade of hematuria, and pathological grade [2]; namely, young age and the absence of hematuria are associated with resistance to TSP. Recently, Ieiri et al. [6] also pointed out that higher age has a favorable impact on the CR rate after TSP. With regards to hematuria, the present study demonstrated that the $\mathrm{CR}$ rate in patients with no hematuria (14 out of $292 \operatorname{IgA}$ nephropathy patients) is only $28.6 \%$ compared to $59.6,56.8$, and $56.1 \%$ in patients with $1+, 2+$, and $3+$ hematuria, respectively. Extensive review of the literature on the relationship between TSP and hematuria revealed no studies except for our previous report [2]. IgA nephropathy patients without hematuria may have nephrosclerosis or hereditary nephritis with concomitant glomerular IgA deposition, because $4 \%$ of normal persons without urinary abnormalities are reported 
to have glomerular IgA deposition on postmortem examination after accidental death [7]. Concomitant glomerular IgA deposition has been reported in hereditary nephritis, including thin basement membrane disease [8-10], mild Alport syndrome [11], focal segmental glomerulosclerosis [12], and complement factor abnormalities [13]. Moreover, the CR rate in patients without proteinuria (mainly hematuria alone) is relatively low, $60.8 \%$ compared to approximately $73.0 \%$ in patients with $0.3-0.69 \mathrm{~g} /$ day of urinary protein. TSP hardly induces CR in these patients of combination with hereditary nephritis and glomerular IgA deposition. We have to pay attention to the diagnostic criteria of IgA nephropathy when patients show no hematuria or no proteinuria because thin basement membrane disease occurs in up to $9 \%$ of the general population according to an analysis of donor kidney grafts [14], and concomitant glomerular IgA deposition is observed in $4 \%$ of normal population [7].

In conclusion, heat maps with the eGFR or pathological grade and daily amount of urinary protein are useful tools for predicting the CR rate of TSP for IgA nephropathy.

Acknowledgments The authors appreciate the contributions to data collection from Dr. Kumiko Moriwaki and Dr. Hideyasu Kiyomoto (Department of Cardiorenal and Cerebrovascular Medicine, Kagawa University Medical School, Kagawa, Japan); Dr. Kentaro Kohagura (Department of Cardiovascular Medicine, Nephrology and Neurology, University of the Ryukyus School of Medicine, Okinawa, Japan); Dr. Eiko Nakazawa and Dr. Eiji Kusano (Division of Nephrology, Department of Internal Medicine, Jichi Medical University, Shimotsuke, Tochigi, Japan); Dr. Toshio Mochizuki (Department of Medicine II, Hokkaido University Graduate School of Medicine, Sapporo, Japan); Dr. Shinsuke Nomura (Departments of Cardiology \& Nephrology and Microbiology, Mie University Graduate School of Medicine, Mie, Japan); Drs. Tamaki Sasaki and Naoki Kashihara (Division of Nephrology and Rheumatology, Department of Internal Medicine, Kawasaki Medical School, 577 Matsushima, Kurashiki, Okayama, Japan); Dr. Jun Soma (Department of Nephrology, Iwate Prefectural Central Hospital, Morioka, Iwate, Japan); Dr. Tadashi Tomo (Department of Internal Medicine II, Oita University Faculty of Medicine, Oita, Japan); Dr. Iwao Nakabayashi and Dr. Masaharu Yoshida (Renal Unit, Department of Internal Medicine, Hachioji Medical Center, Tokyo Medical University, Tokyo, Japan); Dr. Tsuyoshi Watanabe (Third Department of Internal Medicine, Fukushima Medical University, School of Medicine, Fukushima, Japan).

Conflict of interest All the authors have declared no competing interest.

Open Access This article is distributed under the terms of the Creative Commons Attribution License which permits any use, distribution, and reproduction in any medium, provided the original author(s) and the source are credited.

\section{References}

1. Hotta O, Miyazaki M, Furuta T, et al. Tonsillectomy and steroid pulse therapy significantly impact in patients with IgA nephropathy. Am J Kidney Dis. 2001;38:736-42.

2. Miura N, Imai H, Kikuchi S, et al. Tonsillectomy and steroid pulse (TSP) therapy for patients with $\operatorname{IgA}$ nephropathy: a nationwide survey of TSP therapy in Japan and an analysis of the predictive factors for resistance to TSP therapy. Clin Exp Nephrol. 2009;13:460-6.

3. Matsuo S, Imai E, Horio M, et al. Revised equations for estimated GFR from serum creatinine in Japan. Am J Kidney Dis. 2009;53:982-92.

4. Wakai K, Kawamura T, Endoh M, et al. A scoring system to predict renal outcome in $\operatorname{IgA}$ nephropathy: from a nationwide prospective study. Nephrol Dial Transplant. 2006;21:2800-8.

5. Gutiérrez E, Zamora I, Ballarín JA, et al. Long-term outcomes of IgA nephropathy presenting with minimal or no proteinuria. J Am Soc Nephrol. 2012;23:1753-60.

6. Ieiri N, Hotta O, Sato T, Taguma Y. Significance of the duration of nephropathy for achieving clinical remission in patients with IgA nephropathy treated by tonsillectomy and steroid pulse therapy. Clin Exp Nephrol. 2012;16:122-9.

7. Sinniah R. Occurrence of mesangial IgA and IgM deposits in a control necropsy population. J Clin Pathol. 1983;36:276-9.

8. Cosio FG, Falkenhain ME, Sedmak DD. Association of thin glomerular basement membrane with other glomerulopathies. Kidney Int. 1994;46:471-4.

9. Berthoux FC, Laurent B, Alamartine E, et al. New subgroup of primary $\operatorname{IgA}$ nephritis with thin glomerular basement membrane (GBM): syndrome or association. Nephrol Dial Transplant. 1996;11:558-9.

10. Cheong HI, Cho HY, Moon KC, Ha IS, Choi Y. Pattern of double glomerulopathy in children. Pediatr Nephrol. 2007;22:521-7.

11. Kamimura H, Honda K, Nitta K, et al. Glomerular expression of $\alpha 2$ (IV) and $\alpha 5$ (IV) chains of type IV collagen in patients with IgA nephropathy. Nephron. 2002;91:43-50.

12. Hirose $M$, Nishino $T$, Uramatsu $T$, et al. A case of minimal change nephrotic syndrome with immunoglobulin A nephropathy transitioned to focal segmental glomerulosclerosis. Clin Exp Nephrol. 2012;16:473-9.

13. Deltas C, Pierides A, Voskarides K. The role of molecular genetics in diagnosing familial hematuris(s). Pediatr Nephrol. 2012;27:1221-31.

14. Dische FE, Anderson VE, Keane SJ, Taube D, Bewick M, Parsons V. Incidence of thin membrane nephropathy: morphometric investigation of a population sample. J Clin Pathol. 1990;43: 457-60. 